\title{
Experimental Study on Autogenous and Drying Shrinkage of Steel Fiber Reinforced Lightweight-Aggregate Concrete
}

\author{
Shunbo Zhao, Changyong Li, Mingshuang Zhao, and Xiaoyan Zhang \\ School of Civil Engineering and Communication, North China University of Water Resources and Electric Power, No. 36 Beihuan Road, \\ Zhengzhou 450045, China
}

Correspondence should be addressed to Shunbo Zhao; sbzhao@ncwu.edu.cn

Received 6 April 2016; Accepted 20 October 2016

Academic Editor: Osman Gencel

Copyright (C) 2016 Shunbo Zhao et al. This is an open access article distributed under the Creative Commons Attribution License, which permits unrestricted use, distribution, and reproduction in any medium, provided the original work is properly cited.

Steel fiber reinforced lightweight-aggregate concrete (SFRLAC) has many advantages applied in structural engineering. In this paper, the autogenous shrinkage and drying shrinkage of SFRLAC for up to 270 days were measured, considering the effects of types of coarse and fine aggregates with the changes of water-to-binder ratio and volume fraction of steel fiber, respectively. The properties of mix workability, apparent density, and compressive strength of SFRLAC were also reported and discussed in relation to above factors. Test results show that the development of autogenous and drying shrinkage of SFRLAC was fast within 28 days and tended to be steady after 90 days. The development of autogenous shrinkage of SFRLAC reduced with the increasing waterto-binder ratio and by using the expanded shale with higher soundness and good water absorption, especially at early age within 28 days; the later drying shrinkage was reduced and the development of drying shrinkage was slowed down with the increasing volume fraction of steel fiber obviously; manufactured sand led to less autogenous shrinkage but greater drying shrinkage than fine lightweight aggregate in SFRLAC. The regularities of autogenous shrinkage and drying shrinkage of SFRLAC expressed as the series of hyperbola are analyzed.

\section{Introduction}

Shrinkage is a common phenomenon of concrete, which can induce tensile stress when the shrinkage is restrained, and may lead to cracking and finally reduce the service life and durability of concrete structures [1]. With the development of long span, large size, and high rise buildings, the design for considering the influence of concrete shrinkage becomes more and more important [2]. Based on the forming mechanisms, shrinkage can be divided as autogenous shrinkage and drying shrinkage. As the volume of cement hydration products is less than the sum of volumes of water and binders, pores and capillaries formed in the hardened cement paste. Autogenous shrinkage takes place because of the self-desiccation of pores and capillaries, resulting from the continuous hydration of binder materials after initial setting. Drying shrinkage takes place mainly due to the free water evaporated from the pores and capillaries near element surfaces to ambient air. The main factors influencing drying shrinkage are concrete strength, cement type, geometry, curing condition, and starting age [1-4] as well as some properties of concrete mix such as cement dosage, fine aggregate percentage, air content, and slump $[1,3,4]$. The above properties of concrete mix are also the primary factors influencing the autogenous shrinkage of concrete, which determines the composite microstructure of cement paste in concrete. Meanwhile, the coarse aggregate is the bone of concrete, which constrains the shrinkage of concrete in different degrees depending on the type, grading, maximum size, fine aggregate percentage, and volume ratio of aggregate in concrete [5].

In view of the marked shrinkage of normal weight concrete (NWC), especially of high-strength concrete, the internal curing provided by a partial replacement of normal weight aggregate (NWA) by lightweight aggregate (LWA) has been developed as an effective technique for shrinkage mitigation in recent years [6-15]. In this method, the use of prewetted LWAs as internal water sources of concrete is the key of study, as the unsaturated LWAs may lead to an opposite effect due to the absorption of water from matrix 
pores into aggregate pores [7-11]. The saturated LWAs can absorb significant amounts of water before mixing and release the water gradually during concrete hardening. The released water will contribute to restoring part of the water which has been lost through internal self-desiccation or external drying of concrete. However, the efficiency of internal curing by LWAs depends not only on their water absorption but also on their desorption characteristics, as not all kinds of LWA can release a sufficient amount of absorbed water during hardening of concrete, although most of them are able to absorb significant amounts of water because of their high porosity. Generally, the desorption characteristics depend on the microstructures of pores [13], the surface open porosity, and the particle size [14]; a coarse pore structure with a high proportion of well-interconnected pores leads to better desorption behavior for internal curing [15]. Meanwhile, the capability of internal curing of LWAs reduces with the decrease of water-to-binder ratio and the increase of concrete strength [16-18].

Theoretically, if the coarse NWA was fully replaced by the coarse LWA, NWC will become the lightweight aggregate concrete (LAC). As in most cases, structural LAC is made with a LWA as coarse aggregate and normal weight sand (natural river sand or manufactured sand) as the fine aggregate [19]. Therefore, the internal curing of LAC by saturated LWAs should be developed to the best; the difference of shrinkage of LAC to NWC should mainly depend on the difference of properties of coarse aggregates. As reported $[20,21]$ that with the same strength, LAC with higher moisture content LWAs has smaller shrinkage at early age but is finally larger than NWC; however the shrinkage of LAC with lower moisture content LWAs is always larger than that of NWC. When part of the lower water absorption LWAs was replaced by crushed limestone, the shrinkage of LAC could be reduced. This is because, for the same strength, LAC has larger volume of cement paste, and the modulus of elasticity of LWA is lower than that of NWA. However, with the different compositional parameters such as types of LWA (fly ash based artificial aggregate, sintering expanded clay, pumice aggregate, or oil palm shell), amount and type of binder, water-to-binder ratio, mineral admixture (silica fume, fly ash), and initial prewetting method for LWA, the shrinkage of LAC may be lower or greater than that of NWC [22-27]. Generally, the shrinkage of LACs is reduced by the rigid LWA with higher modulus of elasticity in water saturated condition prewetted and with the greater volume of LWA in the same volume of paste [24-26]. And most importantly, in current standard methods, the shrinkage of LAC is usually estimated from the expressions defined for NWC and always gets higher value than those measured in practice [24, 28]. For the proper prediction of shrinkage, the special characteristics of LAC should be considered.

With the application of fiber reinforced LAC in structure engineering, the effects of steel fibers or hybrid fibers on shrinkage of LAC were also studied. Among them, LACs were made by using cold-bonded fly ash aggregate [29], sintered fly ash aggregate [30], and expanded clay aggregate [31-33] as coarse aggregate and river sand as fine aggregate. Generally, the shrinkage of LACs did not change much at early age; however it reduced later to some extent. Fibers (carbon fiber, steel fiber, and polypropylene fiber) in LAC could not change the shrinkage behavior of base LAC affected by LWAs and water-to-binder ratio; their effect is mainly on the restraining of drying shrinkage. As the type and content of fibers are new parameters affecting the shrinkage of LAC, the research become complex and should be carried out comprehensively with other parameters changed.

In view of the wide application of sintering expanded shale as a LWA $[20,21]$ and the inexorable trend of natural sand replaced by manufactured sand $[5,34]$, this paper is focused on the autogenous and drying shrinkages of SFRLAC (steel fiber reinforced LAC) with the change of expanded shale and fine aggregate. The water-to-binder ratio and the volume fraction of steel fiber are taken into consideration to study their effects on autogenous shrinkage and drying shrinkage, respectively. Meanwhile, the mix workability, apparent density, and compressive strength are also given out. The aim of this study is to quantify the effects of aggregates, water-to-binder ratio, and volume fraction on the shrinkage of SFRLAC and finally gives a reference for the practical analysis of structural design.

\section{Experiment}

\subsection{Raw Materials}

Cement: grade P.O. 52.5 ordinary silicate cement produced in accordance with China Standards [35]; the physical and mechanical properties are listed in Table 1.

Admixture: class-II fly ash with physical properties listed in Table 2.

Coarse aggregate: two kinds of ceramsite of sintering expanded shale in continuous gradation with maximum size of $20 \mathrm{~mm}$. They were sieved based on the maximum density principle. The physical and mechanical properties are listed in Table 3.

Fine aggregate: lightweight sand of fine sintering expanded shale and manufactured sand in continuous gradation with size of $1.6-5 \mathrm{~mm}$. The physical properties are listed in Table 4.

Steel fiber: milling type, $36 \mathrm{~mm}$ long, $1.35 \mathrm{~mm}$ equivalent diameter, and 27.1 aspect ratio.

Water reducer: polycarboxylic acid superplasticizer with water-reducing rate of $19 \%$.

Water: tap water.

The water absorption of lightweight aggregates was measured in accordance with China Standard GB/T 17431.2 [36]; the results are drawn in Figure 1.

2.2. Test Parameters and Mix Proportion of Concrete. Test parameters of this study were considered as volume fraction of steel fiber $\left(\rho_{f}\right)$, water-to-binder ratio $(W / B)$, two kinds of coarse lightweight aggregate, and fine lightweight aggregate and manufactured sand [37, 38]. Their combinations for 
TABLE 1: Physical and mechanical properties of cement.

\begin{tabular}{lccccccc}
\hline \multirow{2}{*}{ Strength grade } & \multicolumn{2}{c}{$\begin{array}{c}\text { Water requirement of } \\
\text { normal consistency (\%) }\end{array}$} & \multicolumn{2}{c}{ Setting time (min) } & \multicolumn{2}{c}{ Compressive strength (MPa) } & \multicolumn{2}{c}{ Tensile strength (MPa) } \\
& 27.4 & 150 & 255 & 33.6 & 51.7 & $3 \mathrm{~d}$ & $28 \mathrm{~d}$ \\
\hline 52.5 & & & Final & $3 \mathrm{~d}$ & 28.8 & 9.2 \\
\hline
\end{tabular}

TABLE 2: Physical properties of fly ash.

\begin{tabular}{lccc}
\hline Fineness modulus (pass $0.045 \mathrm{~mm})(\%)$ & Water demand ratio $(\%)$ & Apparent density $\left(\mathrm{kg} / \mathrm{m}^{3}\right)$ & Water content $(\%)$ \\
\hline 26.4 & 104.2 & 2049 & 0.4 \\
\hline
\end{tabular}

TABLE 3: Physical and mechanical properties of expanded shale.

\begin{tabular}{lccccc}
\hline Identifier & Apparent density $\left(\mathrm{kg} / \mathrm{m}^{3}\right)$ & Bulk density $\left(\mathrm{kg} / \mathrm{m}^{3}\right)$ & 1 h water absorption (\%) & Mud content (\%) & $\begin{array}{c}\text { Cylinder compressive } \\
\text { strength (MPa) }\end{array}$ \\
\hline $\mathrm{H}$ & 1444 & 888 & 7.65 & 0.7 & 8.3 \\
$\mathrm{~N}$ & 1307 & 816 & 8.50 & 0.9 & 7.3 \\
\hline
\end{tabular}

TABLE 4: Physical properties of lightweight sand and manufactured sand.

\begin{tabular}{lccccccc}
\hline Identifier & $\begin{array}{c}\text { Grade } \\
(\mathrm{mm})\end{array}$ & $\begin{array}{c}\text { Fineness } \\
\text { modulus }\end{array}$ & $\begin{array}{c}\text { Apparent density } \\
\left(\mathrm{kg} / \mathrm{m}^{3}\right)\end{array}$ & $\begin{array}{c}\text { Bulk density } \\
\left(\mathrm{kg} / \mathrm{m}^{3}\right)\end{array}$ & $\begin{array}{c}\text { 1h water } \\
\text { absorption }(\%)\end{array}$ & $\begin{array}{c}\text { Mud content } \\
(\%)\end{array}$ & $\begin{array}{c}\text { Stone powder } \\
(\%)\end{array}$ \\
\hline $\mathrm{L}$ & $0.16 \sim 5$ & 3.60 & 1350 & 850 & 9.02 & 0.11 & - \\
$\mathrm{M}$ & $0.16 \sim 5$ & 2.82 & 2730 & 2320 & 0.70 & 2.45 \\
\hline
\end{tabular}

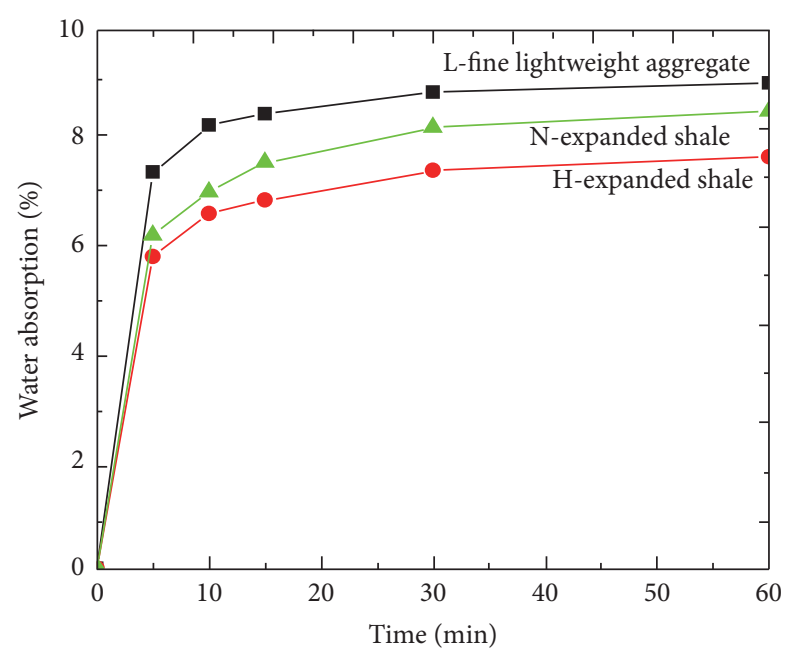

FIGURE 1: Water absorption of lightweight aggregates changing with time.

testing of autogenous shrinkage and drying shrinkage are listed in Table 5, where the double letters of mix number are the identifiers of expanded shale and sand; the following digits represent $W / B$ and $\rho_{f}$.

The mix proportion of SFRLAC was designed in accordance with the specifications in China Standard JGJ 51 [19], where the absolute volume method was selected. For all mixes, the dosages of cement and fly ash were $440 \mathrm{~kg} / \mathrm{m}^{3}$ and $110 \mathrm{~kg} / \mathrm{m}^{3}$; the dosage of water reducer was $5.5 \%$ cement.
2.3. Test Methods. From Figure 1, we can know that the water absorption of lightweight sand at $5 \mathrm{~min}$ reached $81.7 \%$ at 1 hour; the water absorption of ordinary and high-strength expanded shales at 10 min reached $82.4 \%$ and $86.3 \%$ at 1 hour. Therefore, the lightweight sand was prewetted for $5 \mathrm{~min}$; the expanded shales were prewetted for $10 \mathrm{~min}$, before they were put into concrete mixer. The dosage of prewetted water was calculated by the water absorption at 1 hour.

Test for mix slumps was in accordance with the specification of China Standard GB/T50080 [39], which is identical to British Standard BS EN 12350-2-2009 [40].

The apparent density of SFRLAC was measured in accordance with the specification of China Standard JGJ51 [19]. Three cubes were used as a group for each SFRLAC. They were dried to be a steady weight in drying box at $(105 \sim 110)^{\circ} \mathrm{C}$, and then the apparent density was gotten from the weight divided by the volume of cube.

The cubic compressive strength at $28 \mathrm{~d}$ of each group was tested by using the cubes in dimension of $150 \mathrm{~mm}$; each group had three cubes. The cubes were tested on YE-2000A hydraulic compression machine for compressive strength of SFRLAC in accordance with the specifications of China Standard GB/T50081 [41], which is identical to British Standard BS EN 12390-3-2009 [42].

The shrinkage of SFRLAC was measured in accordance with the specification of China Standards GB/T50082 [43], JG/T472 [44], and CECS 13:2009 [45]. As listed in Table 6, six groups of SFRLAC were used to study the autogenous shrinkage; each group had two specimens; eight groups of SFRLAC were used to study the drying shrinkage; each group had three specimens. The measuring device for autogenous 
TABLE 5: Parameters of shrinkage tests and mix proportion of concrete.

\begin{tabular}{|c|c|c|c|c|c|c|c|c|c|}
\hline \multirow{2}{*}{ Mix number } & \multirow{2}{*}{$W / B$} & \multirow{2}{*}{$\rho_{f}(\%)$} & \multirow{2}{*}{ Mix water $\left(\mathrm{kg} / \mathrm{m}^{3}\right)$} & \multicolumn{2}{|c|}{ Expanded shale $\left(\mathrm{kg} / \mathrm{m}^{3}\right)$} & \multicolumn{2}{|c|}{ Sand $\left(\mathrm{kg} / \mathrm{m}^{3}\right)$} & \multicolumn{2}{|c|}{ Shrinkage test } \\
\hline & & & & $\mathrm{N}$ & $\mathrm{H}$ & $\mathrm{L}$ & M & Autogenous & Dry \\
\hline NL0.30/0.8 & 0.30 & 0.8 & 134.8 & 482.5 & 0 & 368.7 & 0 & $\sqrt{ }$ & $\sqrt{ }$ \\
\hline NM0.30/0.8 & 0.30 & 0.8 & 134.8 & 482.5 & 0 & 0 & 745.6 & $\sqrt{ }$ & $\sqrt{ }$ \\
\hline НМ0.30/0.8 & 0.30 & 0.8 & 134.8 & 0 & 533.1 & 0 & 745.6 & $\sqrt{ }$ & $\sqrt{ }$ \\
\hline HL0.30/0.4 & 0.30 & 0.4 & 134.8 & 0 & 542.2 & 370.9 & 0 & & $\sqrt{ }$ \\
\hline HL0.30/0.8 & 0.30 & 0.8 & 134.8 & 0 & 533.0 & 368.7 & 0 & $\sqrt{ }$ & $\sqrt{ }$ \\
\hline HL0.30/1.2 & 0.30 & 1.2 & 134.8 & 0 & 523.9 & 366.4 & 0 & & $\sqrt{ }$ \\
\hline HL0.30/1.6 & 0.30 & 1.6 & 134.8 & 0 & 514.8 & 364.1 & 0 & & $\sqrt{ }$ \\
\hline HL0.30/2.0 & 0.30 & 2.0 & 134.8 & 0 & 505.6 & 361.9 & 0 & & $\sqrt{ }$ \\
\hline HL0.35/0.8 & 0.35 & 0.8 & 157.2 & 0 & 514.2 & 355.9 & 0 & $\sqrt{ }$ & \\
\hline HL0.25/0.8 & 0.25 & 0.8 & 112.3 & 0 & 551.8 & 381.4 & 0 & $\sqrt{ }$ & \\
\hline
\end{tabular}

TABLE 6: Test results of mix slump and apparent density of SFRLAC.

\begin{tabular}{|c|c|c|c|c|}
\hline \multirow{2}{*}{ Mix number } & \multirow{2}{*}{ Slump (mm) } & \multicolumn{2}{|c|}{ Apparent density $\left(\mathrm{kg} / \mathrm{m}^{3}\right)$} & \multirow{2}{*}{ Cubic compressive strength $(\mathrm{MPa})$} \\
\hline & & Wet & Dry & \\
\hline HL0.3/0.4 & 165 & 1754 & 1695 & 47.2 \\
\hline HL0.3/0.8 & 197 & 1809 & 1753 & 49.3 \\
\hline HL0.3/1.2 & 170 & 1842 & 1784 & 57.6 \\
\hline HL0.3/1.6 & 98 & 1843 & 1787 & 60.9 \\
\hline HL0.3/2.0 & 46 & 1919 & 1843 & 64.8 \\
\hline HL0.25/0.8 & 35 & 1820 & 1783 & 59.3 \\
\hline HL0.35/0.8 & 175 & 1796 & 1696 & 47.8 \\
\hline HМ0.3/0.8 & 85 & 2069 & 1946 & 51.7 \\
\hline NL0.3/0.8 & 150 & 1682 & 1651 & 45.0 \\
\hline NM0.3/0.8 & 75 & 2000 & 1869 & 54.1 \\
\hline
\end{tabular}

shrinkage is shown in Figure 2; the specimen is $\varnothing 150 \mathrm{~mm}$ $\times 450 \mathrm{~mm}$ cylinder. Two micrometer gauges were fixed symmetrically on the specimen accompanying the copper rods by using the embedded gaging heads with standard datum length of $250 \mathrm{~mm}$. The specimens were placed in the standard curing room with $(20 \pm 2)^{\circ} \mathrm{C}$ temperature and $(65 \pm$ $5) \%$ RH. The cast surface was covered by wet cloth. After cast for 12 hours, they were demolded and closely wrapped with polypropylene plastic film. The measuring started at 24 hours after specimen cast.

The prisms in dimension of $100 \mathrm{~mm} \times 100 \mathrm{~mm} \times 550 \mathrm{~mm}$ were used to measure the drying shrinkage. The copper ends were embedded at specimen ends along the longitudinal centroidal axis. The prisms were demolded after casting for 12 hours and placed into the standard curing box shown in Figure 3(a) with $(20 \pm 2)^{\circ} \mathrm{C}$ temperature and $(60 \pm 5) \% \mathrm{RH}$. The length comparator shown in Figure 3(b) was used to measure the specimen length due to drying shrinkage. The measuring started at 24 hours after specimen cast.

\section{Results and Analysis}

3.1. Mix Workability. Test results of mix slump are listed in Table 6. As tests reported [37], the mix slump tended to reduce with the increase of volume fraction of steel fiber. This is mainly due to the bridging effect of steel fiber;

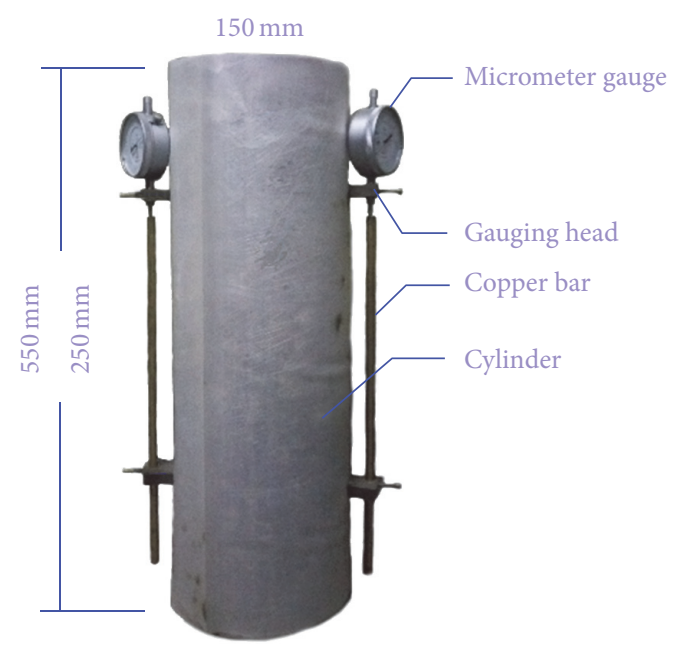

FIGURE 2: Measuring device for autogenous deformation.

the mix flowability increased normally when the mix was vibrated. The mix slump was affected by water-to-binder ratio obviously; the mix with $W / B=0.25$ did not satisfy the requirement of flowing concrete. Meanwhile, the mixes with manufactured sand had lower slump; this is reasonable because of the peculiarity of manufactured sand with rough 


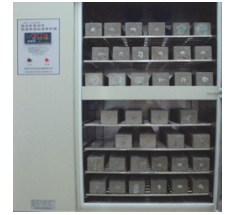

(a) Standard curing box

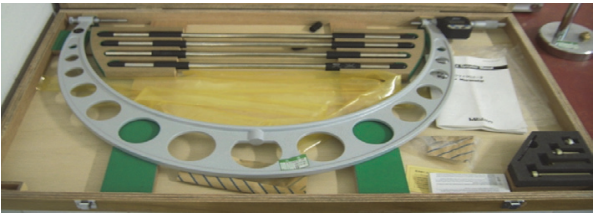

(b) Length comparator

FIGURE 3: Devices for drying shrinkage of specimen.

surface, corner angles, and stone powder [34, 38]. Compared with the mix with $\mathrm{H}$-expanded shale, the mix with $\mathrm{N}$ expanded shale had lower slump. This is because of the larger specific surface area of $\mathrm{N}$-expanded shale with lower density.

3.2. Apparent Density and Compressive Strength. As can be seen from Table 6 , due to the high density of steel fiber and design by the absolute volume method, the apparent density of SFRLAC increased with the volume fraction of steel fiber. With the $0.4 \%$ increment of volume fraction of steel fiber, the apparent density increased by $1 \sim 3 \%$ with an average of 2.2\%; however the dry apparent density of SFRLAC with lightweight sand was lower than $1850 \mathrm{~kg} / \mathrm{m}^{3}$. With the increase of $W / B$, the density of SFRLAC reduced somewhat. The density of SFRLAC with manufactured sand was heavy; fortunately it was also within the specified range of LAC less than $1950 \mathrm{~kg} / \mathrm{m}^{3}$ [19].

As tests reported [37], the compressive strength of SFRLAC increased with the volume fraction of steel fiber and decreased with the increase of $W / B$. SFRLAC with manufactured sand had higher compressive strength than that with lightweight sand.

3.3. Autogenous Shrinkage. Test results of autogenous shrinkage of SFRLAC for up to 270 days are listed in Table 7 and shown in Figure 4. As can be seen in this table and figure, the development of autogenous shrinkage of SFRLAC was fast within 28 days and tended to be steady after 90 days. For the SFRLAC with $\mathrm{H}$-expanded shale and L-fine aggregate, the autogenous shrinkage grew slowly with the increasing $W / B$, especially at early age within 28 days; this is because of the cement hydration water supplied by sufficient free water in pores of SFRLAC with larger $W / B$, resulting in the moist pores and capillaries with less pore shrinkage stress. With the same $W / B$ and L-fine lightweight aggregate, the autogenous shrinkage of SFRLAC with $\mathrm{N}$-expanded shale developed fast within 28 days and was overall larger than that of SFRLAC with $\mathrm{H}$-expanded shale; this is mainly due to the less compressive strength of $\mathrm{N}$-expanded shale resulting from the weaker particle soundness, resulting in the bad resisting to the shrinkage deformation. Compared to SFRLAC mixed with L-fine lightweight aggregate, SFRLAC mixed with manufactured sand (M-sand) had smaller autogenous shrinkage; this may be due to the higher particle soundness of M-sand filed into the pores of expanded shales to constrain the autogenous deformation and the better interfacial bond property between cement paste and particles

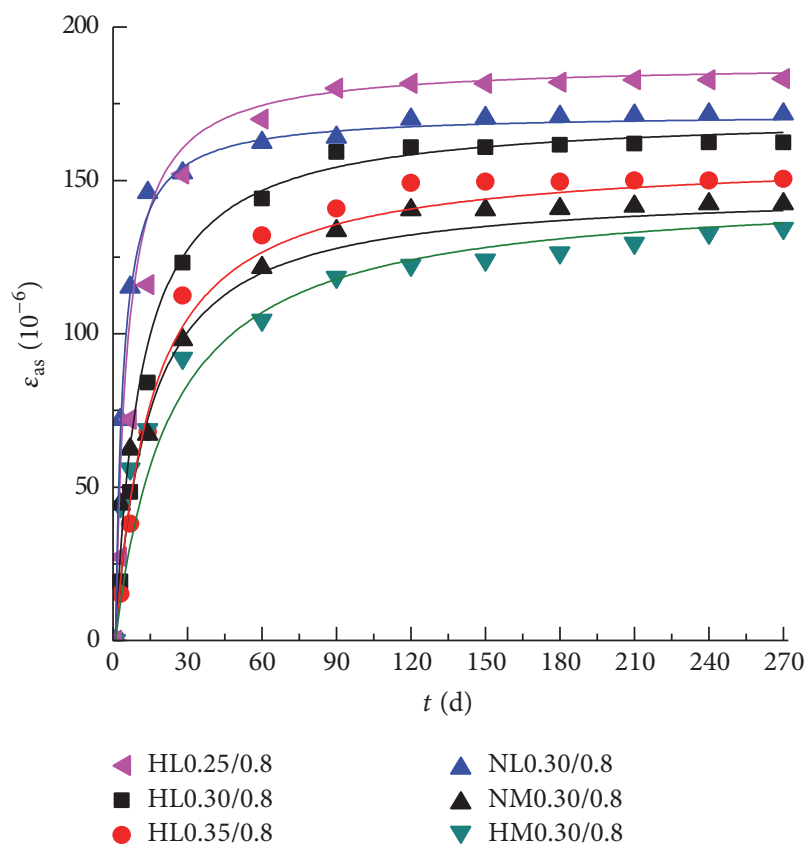

FIgURE 4: Autogenous shrinkage of SFRLAC.

of manufactured sand [5, 38]; all of these are beneficial to reduce the autogenous shrinkage of SFRLAC.

Based on the statistical analysis of test data, the regularity of autogenous shrinkage of SFRLAC can be expressed well as a series of hyperbola:

$$
\begin{aligned}
& \varepsilon_{\text {as }}\left(t, t_{s}\right) \\
& =\frac{360\left(t-t_{s}\right) \times 10^{-6}}{52.5\left(\alpha_{1} \beta_{1} \cdot 4.68(W / B)-1\right)+\left(1+\alpha_{2} \beta_{2} \cdot 3.65(W / B)\right)\left(t-t_{s}\right)},
\end{aligned}
$$

where $\varepsilon_{\text {as }}\left(t, t_{s}\right)$ is the autogenous shrinkage of SFRLAC at $t$ age and $t_{s}$ is the initial age for the testing of autogenous shrinkage, here taken as 1 day after molding. $\alpha_{1}\left(\alpha_{2}\right)$ and $\beta_{1}\left(\beta_{2}\right)$ are the shape factors related to coarse aggregate and fine aggregate, respectively; they are listed in Table 8.

The comparison of formula (1) with test results is also shown in Figure 4, which fitted better with correlation coefficient greater than 0.90 .

From formula (1), it can be concluded that $W / B$ is a main factor influencing not only the development rate at early age, but also the later developing state of autogenous shrinkage. As can be seen from Table 8, the effects of 
TABLE 7: Test results of autogenous shrinkage of SFRLAC.

\begin{tabular}{|c|c|c|c|c|c|c|c|c|c|c|c|c|c|}
\hline \multirow{2}{*}{ Mix number } & \multicolumn{13}{|c|}{ Curing age (days) } \\
\hline & 1 & 3 & 7 & 14 & 28 & 60 & 90 & 120 & 150 & 180 & 210 & 240 & 270 \\
\hline HL0.25/0.8 & 0 & 27 & 72 & 116 & 152 & 170 & 180 & 182 & 182 & 182 & 183 & 183 & 183 \\
\hline HL0.30/0.8 & 0 & 19 & 48 & 84 & 123 & 144 & 159 & 161 & 161 & 162 & 162 & 162 & 162 \\
\hline HL0.35/0.8 & 0 & 15 & 38 & 68 & 112 & 132 & 141 & 149 & 150 & 150 & 150 & 150 & 150 \\
\hline NL0.30/0.8 & 0 & 72 & 115 & 146 & 152 & 162 & 164 & 170 & 170 & 171 & 171 & 172 & 172 \\
\hline HM0.30/0.8 & 0 & 44 & 56 & 69 & 92 & 104 & 118 & 122 & 124 & 126 & 130 & 133 & 134 \\
\hline NM0.30/0.8 & 0 & 44 & 62 & 67 & 98 & 121 & 134 & 140 & 140 & 141 & 142 & 142 & 142 \\
\hline
\end{tabular}

TABLE 8: Values of influencing factors in formula (1).

\begin{tabular}{lcccc}
\hline \multirow{2}{*}{ Aggregate type } & \multicolumn{2}{c}{ Coarse aggregate } & \multicolumn{2}{c}{ Fine aggregate } \\
& $\mathrm{H}$ & $\mathrm{N}$ & $\mathrm{L}$ & $\mathrm{M}$ \\
\hline$\alpha_{1}\left(\alpha_{2}\right)$ & $1.0(1.0)$ & $0.8(1.0)$ & - & - \\
$\beta_{1}\left(\beta_{2}\right)$ & - & - & $1.0(1.0)$ & $1.45(1.32)$ \\
\hline
\end{tabular}

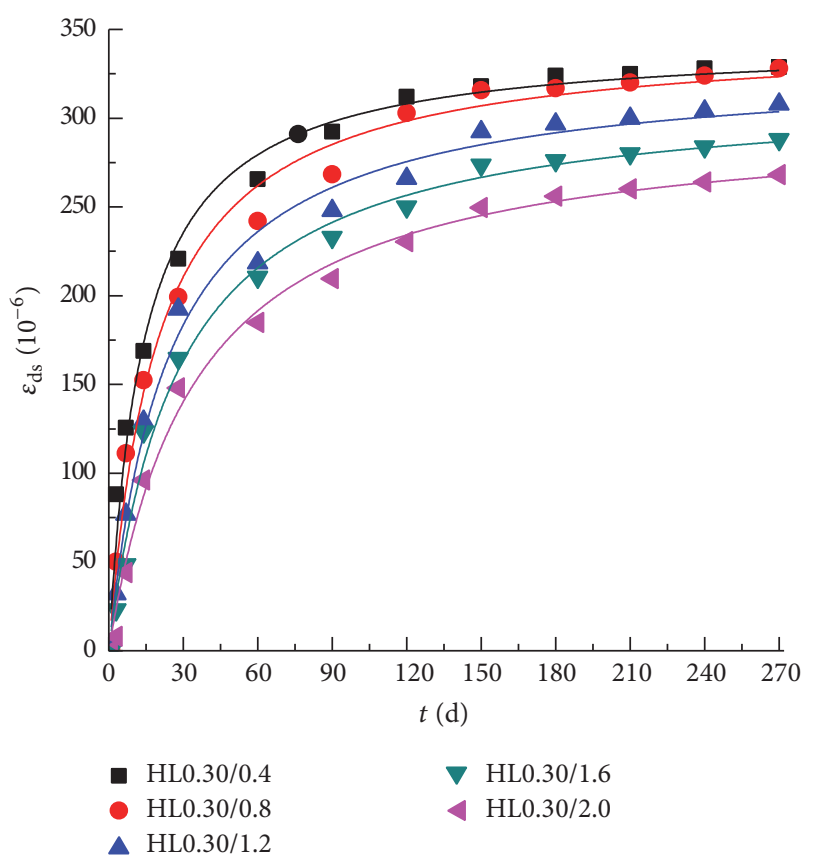

FIGURE 5: Drying shrinkage of SFRLAC with different volume fraction of steel fiber.

different type of aggregate on the autogenous shrinkage of SFRLAC are well reflected by the changes of influencing factors. Under the same condition of other parameters, and compared to the SFRLAC with H-expanded shale and Lfine lightweight aggregate, $\mathrm{N}$-expanded shale increases the development of autogenous shrinkage at early age; M-sand decreases the development rate at early age but prolongs the later developing stage.

3.4. Drying Shrinkage. Test results of drying shrinkage of SFRLAC for up to 270 days are listed in Table 9. As can be seen in this table and Figure 5, the development of drying shrinkage of SFRLAC was slowed down with the increasing volume fraction of steel fiber. The three-dimensional distribution of steel fibers in concrete builds the frame constraining the shrinkage deformation of concrete; this effect will be stronger with the increasing volume fraction of steel fiber due to the better and better net structure bridged among steel fibers. As the large elastic modulus and tensile strength of steel fibers, the constraining effects of steel fiber on the drying shrinkage of SFRLAC were obvious.

Based on the statistical analysis of test data, the regularity of drying shrinkage of SFRLAC with different volume fraction of steel fiber can be expressed as a series of hyperbola:

$$
\varepsilon_{\mathrm{ds}}\left(t, t_{s}\right)=\frac{a\left(t-t_{s}\right)}{b+\left(t-t_{s}\right)} \times 10^{-6},
$$

where $\varepsilon_{\mathrm{ds}}\left(t, t_{s}\right)$ is the drying shrinkage of SFRLAC at $t$ age and $t_{s}$ is the initial age for the testing of autogenous shrinkage, here taken as 1 day after molding. $a$ and $b$ are the shape factors related to the volume fraction of steel fiber.

From formula (2), the shape factors $a$ and $b$ can be obtained by the fitting analysis of test data shown in Figure 5 . After that, the linear relation of them with volume fraction of steel fiber can be obtained as follows and is shown in Figure 6:

$$
\begin{aligned}
& a=5\left(73.4-5.7 \rho_{f}\right), \\
& b=8.91+12.53 \rho_{f} .
\end{aligned}
$$

Combined with formula (2), factor $a$ decreases and $b$ increases with the increase of volume fraction of steel fiber. This means that the later drying shrinkage will be reduced and the development of drying shrinkage will be slowed down by the strong restraint effect of steel fibers, respectively. The comparison of formula (2) with test results of SFRLAC with different volume fraction of steel fiber is drawn in Figure 7, which fitted better with correlation coefficient greater than 0.90 .

Similar to the development of autogenous shrinkage, with the same water-to-binder ratio and L-fine lightweight aggregate, the drying shrinkage of SFRLAC with $\mathrm{N}$-expanded shale developed fast within 28 days and was overall greater than that of SFRLAC with $\mathrm{H}$-expanded shale. This showed that the constraining effect of steel fibers on shrinkage deformation of SFRLAC could not change the inherent shrinkage of base LAC formed by cement paste and aggregate. Compared to SFRLAC mixed with L-fine lightweight aggregate, SFRLAC mixed with manufactured sand (M-sand) had greater drying 
TABLE 9: Test results of drying shrinkage of SFRLAC.

\begin{tabular}{|c|c|c|c|c|c|c|c|c|c|c|c|c|c|}
\hline \multirow{2}{*}{ Mix number } & \multicolumn{13}{|c|}{ Curing age (days) } \\
\hline & 1 & 3 & 7 & 14 & 28 & 60 & 90 & 120 & 150 & 180 & 210 & 240 & 270 \\
\hline HL0.30/0.4 & 0 & 88 & 126 & 169 & 221 & 266 & 292 & 312 & 318 & 320 & 325 & 328 & 329 \\
\hline HL0.30/0.8 & 0 & 50 & 111 & 152 & 199 & 242 & 268 & 303 & 316 & 317 & 320 & 324 & 328 \\
\hline HL0.30/1.2 & 0 & 32 & 77 & 129 & 192 & 218 & 248 & 266 & 292 & 297 & 300 & 304 & 308 \\
\hline HL0.30/1.6 & 0 & 23 & 48 & 123 & 165 & 210 & 233 & 250 & 274 & 276 & 280 & 284 & 288 \\
\hline HL0.30/2.0 & 0 & 8 & 44 & 96 & 148 & 185 & 210 & 230 & 250 & 256 & 260 & 264 & 268 \\
\hline NL0.30/0.8 & 0 & 109 & 124 & 184 & 225 & 272 & 298 & 323 & 343 & 344 & 345 & 345 & 348 \\
\hline НМ0.30/0.8 & 0 & 84 & 137 & 202 & 283 & 329 & 355 & 376 & 382 & 392 & 400 & 400 & 400 \\
\hline NM0.30/0.8 & 0 & 129 & 257 & 325 & 361 & 408 & 436 & 464 & 480 & 484 & 488 & 496 & 505 \\
\hline
\end{tabular}

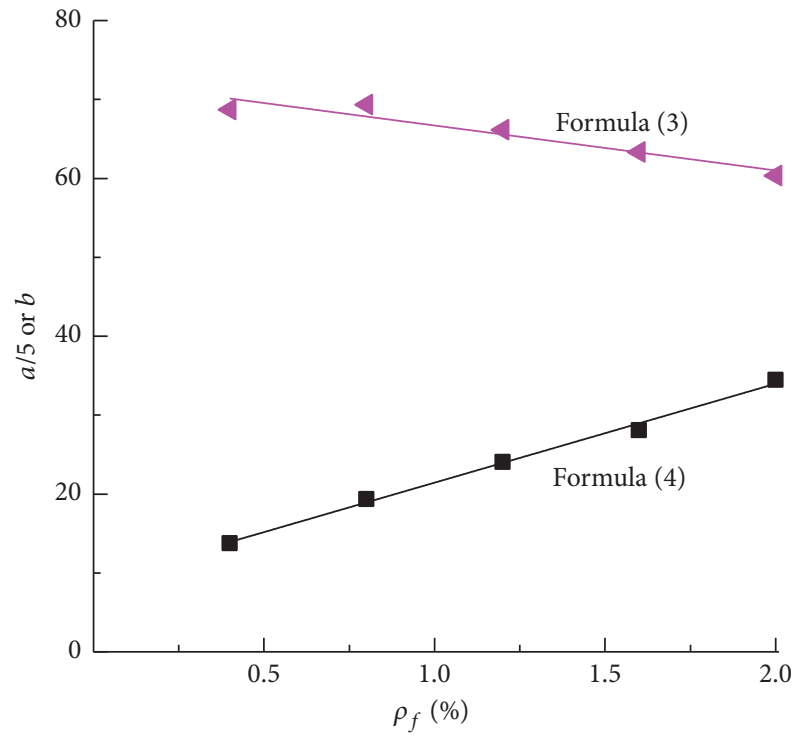

FIGURE 6: Relation of shape factors $a$ and $b$ with volume fraction of steel fiber.

shrinkage. This is because of the larger water absorption of L-fine lightweight aggregate leading to the beneficial internal curing for cement hydration. In this case, the beneficial effects such as the rigid particle of $\mathrm{M}$-sand filling into the pores of expanded shales to constrain the autogenous deformation and the better interfacial bond property between cement paste and particles of M-sand become secondary.

Based on the statistical analysis of test data, the regularity of drying shrinkage of SFRLAC with different aggregates can also be expressed as a series of hyperbola. On the basis of formula (2), it is

$$
\varepsilon_{\mathrm{ds}}\left(t, t_{s}\right)=\frac{\alpha a\left(t-t_{s}\right)}{\beta b+\left(t-t_{s}\right)} \times 10^{-6},
$$

where $\alpha$ and $\beta$ are the influencing factors related to coarse aggregate and fine aggregate.

Results of statistical analysis for values of influencing factors in formula (5) are listed in Table 10. The comparisons of test data with computation of formula (5) are shown in Figure 8. As can be seen from Table 10, the values of influencing factors $\alpha$ and $\beta$ for SFRLAC with $\mathrm{N}$-expanded

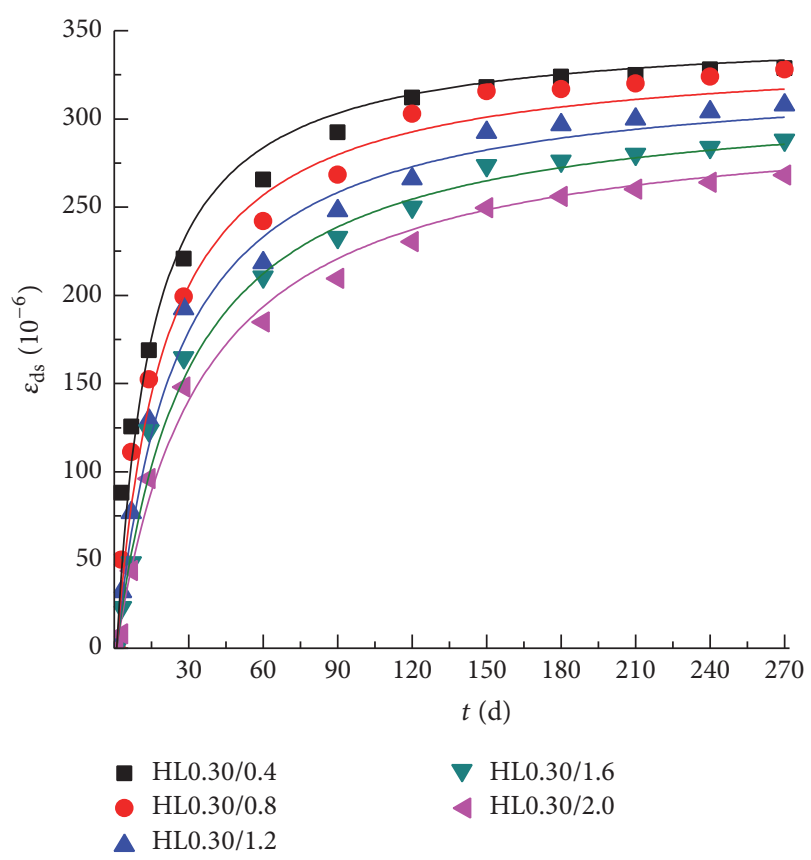

FIGURE 7: Comparison of test data with computation of formula (2).

TABLE 10: Values of influencing factors in formula (5).

\begin{tabular}{lcccc}
\hline \multirow{2}{*}{ Aggregate type } & \multicolumn{4}{c}{ Coarse aggregate $*$ fine aggregate } \\
& $\mathrm{H} * \mathrm{~L}$ & $\mathrm{~N} * \mathrm{~L}$ & $\mathrm{H} * \mathrm{M}$ & $\mathrm{N} * \mathrm{M}$ \\
\hline$\alpha$ & 1.0 & 1.04 & 1.22 & $1.45>1.04 \times 1.22=1.27$ \\
$\beta$ & 1.0 & 0.71 & 0.77 & $0.45<0.71 \times 0.77=0.55$ \\
\hline
\end{tabular}

shale/M-sand are not equal to the product of those for SFRLAC, respectively, with $\mathrm{N}$-expanded shale/L-fine lightweight aggregate and with $\mathrm{H}$-expanded shale/M-sand. This means that the influences of expanded shale and fine aggregate (sand) on drying shrinkage of SFRLAC were correlated. In this study, the drying shrinkage of SFRLAC with $\mathrm{N}$-expanded shale and $\mathrm{M}$-sand was largest.

\section{Conclusions}

From this study, the main conclusions can be given as follows. 


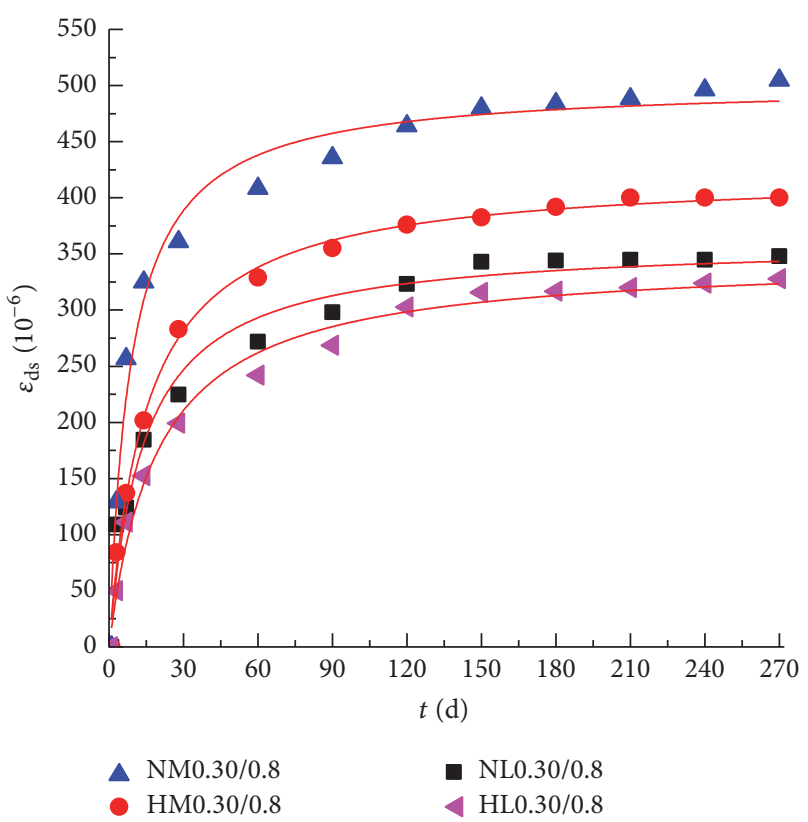

Figure 8: Comparison of test data with computation of formula (5).

(1) The mix slump was affected by water-to-binder ratio obviously and tended to reduce with the increase of volume fraction of steel fiber. Mixes with $\mathrm{N}$-expanded shale or manufactured sand had lower slump.

(2) The apparent density of SFRLAC increased with the volume fraction of steel fiber and reduced somewhat with the increase of $W / B$; however it was less than $1850 \mathrm{~kg} / \mathrm{m}^{3}$ or $1950 \mathrm{~kg} / \mathrm{m}^{3}$ by using lightweight sand or manufactured sand, respectively. The compressive strength of SFRLAC increased with the volume fraction of steel fiber and decreased with the increasing $W / B$, while it was higher with manufactured sand than that with lightweight sand.

(3) Test results of autogenous shrinkage of SFRLAC for up to 270 days are given out. The development of autogenous shrinkage of SFRLAC was fast within 28 days and tended to be steady after 90 days. The autogenous shrinkage of SFRLAC with $\mathrm{H}$-expanded shale and L-fine aggregate grew slowly with the increasing $W / B$, especially at early age within 28 days. With lower compressive strength than that of H-expanded shale, $\mathrm{N}$-expanded shale resulted in the fast development within 28 days and overall greater autogenous shrinkage of SFRLAC. However, L-fine lightweight aggregate led to greater autogenous shrinkage than manufactured sand in SFRLAC.

Based on the test data, the regularity of autogenous shrinkage of SFRLAC can be expressed well as a series of hyperbola, in which the effects of $W / B$, coarse aggregate, and fine aggregate are independently qualified on the development rate at early age and the later developing state of autogenous shrinkage.

(4) Test results of drying shrinkage of SFRLAC for up to 270 days are presented. The later drying shrinkage was reduced and the development of drying shrinkage was slowed down with the increasing volume fraction of steel fiber obviously. Similar to the development of autogenous shrinkage, N-expanded shale leads to the fast development within 28 days and overall greater drying shrinkage than $\mathrm{H}$-expanded shale in SFRLAC. But the internal curing of L-fine lightweight aggregate was more beneficial to reduce the drying shrinkage compared with manufactured sand in SFRLAC.

Based on the test data, the regularity of drying shrinkage of SFRLAC can be also expressed as a series of hyperbola in which the shape factors are linear with the volume fraction of steel fiber, and the influencing factors of coarse aggregate and fine aggregate are qualified. The values of influencing factors show that the effects of these two expanded shales, fine lightweight aggregate and manufactured sand, on drying shrinkage of SFRLAC were correlated. In this study, the drying shrinkage of SFRLAC with $\mathrm{N}$-expanded shale and $\mathrm{M}$ sand was largest.

\section{Competing Interests}

The authors declare that they have no competing interests.

\section{Acknowledgments}

This study was financially supported by the Science and Technology Innovation Team of Eco-Building Material and Structural Engineering in the University of Henan Province, China (13IRTSTHN002), and the Key Research Project of University in Henan Province, China (16A560024).

\section{References}

[1] ACI Committee 209, Prediction of creep, shrinkage and temperature effects in concrete structures, ACI, 209R: Manual of concrete practice, Part 1, 1992.

[2] GB 50010-2010, Code for Design of Concrete Structures, China Building Industry Press, Beijing, China, 2010.

[3] EN, "Eurocode 2: design of concrete structures-part 1.1: general rules and rules for buildings," EN 1992-1-1, CEN, Brussels, Belgium, 2004.

[4] CEB-FIP Model Code 2010-Fib Bulletin 55, First Complete Draft, Vol. 1, Fib-International Federation for Structural Concrete, Lausanne, Switzerland, 2010.

[5] F. L. Li, C. J. Liu, L. Y. Pan, and C. Y. Li, Machine-Made Sand Concrete, China Water Power Press, Beijing, China, 2013.

[6] S. Weber and H. W. Reinhardt, "New generation of high performance concrete: concrete with autogeneous curing," Advanced Cement Based Materials, vol. 6, no. 2, pp. 59-68, 1997.

[7] T. Merikallio, R. Mannonen, and V. Penttala, "Drying of lightweight concrete produced from crushed expanded clay aggregates," Cement and Concrete Research, vol. 26, no. 9, pp. $1423-1433,1996$.

[8] B. Akcay and M. A. Tasdemir, "Effects of distribution of lightweight aggregates on internal curing of concrete," Cement and Concrete Composites, vol. 32, no. 8, pp. 611-616, 2010.

[9] M. Golias, J. Castro, and J. Weiss, "The influence of the initial moisture content of lightweight aggregate on internal curing," Construction and Building Materials, vol. 35, pp. 52-62, 2012.

[10] A. Bentur, S.-I. Igarashi, and K. Kovler, "Prevention of autogenous shrinkage in high-strength concrete by internal curing using wet lightweight aggregates," Cement and Concrete Research, vol. 31, no. 11, pp. 1587-1591, 2001. 
[11] T. Ji, D.-D. Zheng, X.-F. Chen, X.-J. Lin, and H.-C. Wu, "Effect of prewetting degree of ceramsite on the early-age autogenous shrinkage of lightweight aggregate concrete," Construction and Building Materials, vol. 98, pp. 102-111, 2015.

[12] D. Cusson and T. Hoogeveen, "Internal curing of highperformance concrete with pre-soaked fine lightweight aggregate for prevention of autogenous shrinkage cracking," Cement and Concrete Research, vol. 38, no. 6, pp. 757-765, 2008.

[13] S. Ghourchian, M. Wyrzykowski, P. Lura, M. Shekarchi, and B. Ahmadi, "An investigation on the use of zeolite aggregates for internal curing of concrete," Construction and Building Materials, vol. 40, pp. 135-144, 2013.

[14] Y. Wei, Y. Xiang, and Q. Zhang, "Internal curing efficiency of prewetted LWFAs on concrete humidity and autogenous shrinkage development," Journal of Materials in Civil Engineering, vol. 26, no. 5, pp. 947-954, 2014.

[15] S.-D. Hwang, K. H. Khayat, and D. Youssef, "Effect of moist curing and use of lightweight sand on characteristics of highperformance concrete," Materials and Structures, vol. 46, no. 1-2, pp. 35-46, 2013.

[16] J. Zhang, Y. D. Han, Y. Gao, and Y. Luosun, "Integrative study on the effect of internal curing on autogenous and drying shrinkage of high-strength concrete," Drying Technology, vol. 31, no. 5, pp. 565-575, 2013.

[17] J. Zhang, J. H. Wang, and Y. D. Han, "Simulation of moisture field of concrete with pre-soaked lightweight aggregate addition," Construction and Building Materials, vol. 96, pp. 599-614, 2015.

[18] I. Maruyama, M. Kanematsu, T. Noguchi, H. Iikura, A. Teramoto, and H. Hayano, "Evaluation of water transfer from saturated lightweight aggregate to cement paste matrix by neutron radiography," Nuclear Instruments and Methods in Physics Research Section A: Accelerators, Spectrometers, Detectors and Associated Equipment, vol. 605, no. 1-2, pp. 159-162, 2009.

[19] JGJ, “Technical specification for lightweight concrete," JGJ 512002, China Building Industry Press, Beijing, China, 2002.

[20] H. Sun, L. Ye, J. Ding, and Y. Guo, "Shrinkage and creep of highstrength lightweight aggregate concrete," Journal of Tsinghua University, vol. 47, no. 6, pp. 765-767, 2007.

[21] P.-J. Song, J.-T. Ding, and Y.-S. Guo, "Shrinkage of high strength lightweight aggregate concrete and factors influencing it," Journal of Building Materials, vol. 7, no. 2, pp. 138-144, 2004.

[22] A. Nilsen and P. C. Aitcin, "Properties of high-strength concrete containing light-, normal-, and heavyweight aggregate," Cement, Concrete and Aggregates, vol. 14, no. 1, pp. 8-12, 1992.

[23] A. Terzić, L. Pezo, V. Mitić, and Z. Radojević, "Artificial fly ash based aggregates properties influence on lightweight concrete performances," Ceramics International, vol. 41, no. 2, pp. 27142726, 2015.

[24] J. A. Bogas, R. Nogueira, and N. G. Almeida, "Influence of mineral additions and different compositional parameters on the shrinkage of structural expanded clay lightweight concrete," Materials and Design, vol. 56, pp. 1039-1048, 2014.

[25] P. Shafigh, H. Ghafari, H. B. Mahmud, and M. Z. Jumaat, "A comparison study of the mechanical properties and drying shrinkage of oil palm shell and expanded clay lightweight aggregate concretes," Materials and Design, vol. 60, pp. 320-327, 2014.

[26] N. Kabay and F. Aköz, "Effect of prewetting methods on some fresh and hardened properties of concrete with pumice aggregate," Cement and Concrete Composites, vol. 34, no. 4, pp. 503-507, 2012.
[27] A. I. M. Ismail, M. S. Elmaghraby, and H. S. Mekky, "Engineering properties, microstructure and strength development of lightweight concrete containing pumice aggregates," Geotechnical and Geological Engineering, vol. 31, no. 5, pp. 1465-1476, 2013.

[28] H. Costa, E. Júlio, and J. Loureno, "New approach for shrinkage prediction of high-strength lightweight aggregate concrete," Construction and Building Materials, vol. 35, pp. 84-91, 2012.

[29] E. Güneyisi, M. Gesoğlu, A. Mohamadameen, R. Alzeebaree, Z. Algın, and K. Mermerdaş, "Enhancement of shrinkage behavior of lightweight aggregate concretes by shrinkage reducing admixture and fiber reinforcement," Construction and Building Materials, vol. 54, pp. 91-98, 2014.

[30] L. Domagała, "Modification of properties of structural lightweight concrete with steel fibres," Journal of Civil Engineering and Management, vol. 17, no. 1, pp. 36-44, 2011.

[31] O. Kayali, M. N. Haque, and B. Zhu, "Drying shrinkage of fibrereinforced lightweight aggregate concrete containing fly ash," Cement and Concrete Research, vol. 29, no. 11, pp. 1835-1840, 1999.

[32] B. Chen and J. Liu, "Contribution of hybrid fibers on the properties of the high-strength lightweight concrete having good workability," Cement and Concrete Research, vol. 35, no. 5, pp. 913-917, 2005.

[33] B. Chen and J. Liu, "Properties of lightweight expanded polystyrene concrete reinforced with steel fiber," Cement and Concrete Research, vol. 34, no. 7, pp. 1259-1263, 2004.

[34] X. X. Ding, C. Y. Li, Y. Y. Xu, F. L. Li, and S. B. Zhao, "Experimental study on long-term compressive strength of concrete with manufactured sand," Construction and Building Materials, no. 108, pp. 67-73, 2016.

[35] SAC, "Common Portland cement," GB 175-2007, Standardization Administration of China, Beijing, China, 2007.

[36] GB/T, "Test method for lightweight aggregate," GB/T 17431.22010, China Standard Press, Beijing, China, 2010.

[37] Z. Shen, M. H. Chen, M. S. Zhao, and X. K. Li. Experimental study, "Experimental study on tensile properties of steel fiber reinforced lightweight-aggregate fly-ash flowable concrete," in Architectural Engineering and New Materials, pp. 1-8, DEStech, 2015.

[38] S. Zhao, Y. Xu, and C. Li, "Study on workability of plastic fresh concrete with machine-made sand," in Proceedings of the International Conference on Transportation, Mechanical, and Electrical Engineering (TMEE '11), pp. 2013-2016, Changchun, China, December 2011.

[39] GB/T, "Standard for test method of performance on ordinary fresh concrete," GB/T 50080-2002, China Building Industry Press, Beijing, China, 2002.

[40] BS EN, “Testing fresh concrete-slump-test," BS EN 12350-22009, 2009.

[41] CABP, "Standard for test method of mechanical properties on ordinary concrete," GB/T 50081-2002, China Architecture and Building Press, Beijing, China, 2002.

[42] "Testing hardened concrete-compressive strength of test specimens," BS EN 12390-3-2009, 2009.

[43] GB/T, "Standard for test method of long-term performance and durability of ordinary concrete," GB/T 50082-2009, China Building Industry Press, Beijing, China, 2010.

[44] “Steel fiber reinforced concrete," JG/T 472-2015, China Building Industry Press, Beijing, China, 2015.

[45] CECS, "Standard test methods for fiber reinforced concrete," CECS 13:2009, China Plan Press, Beijing, China, 2010. 

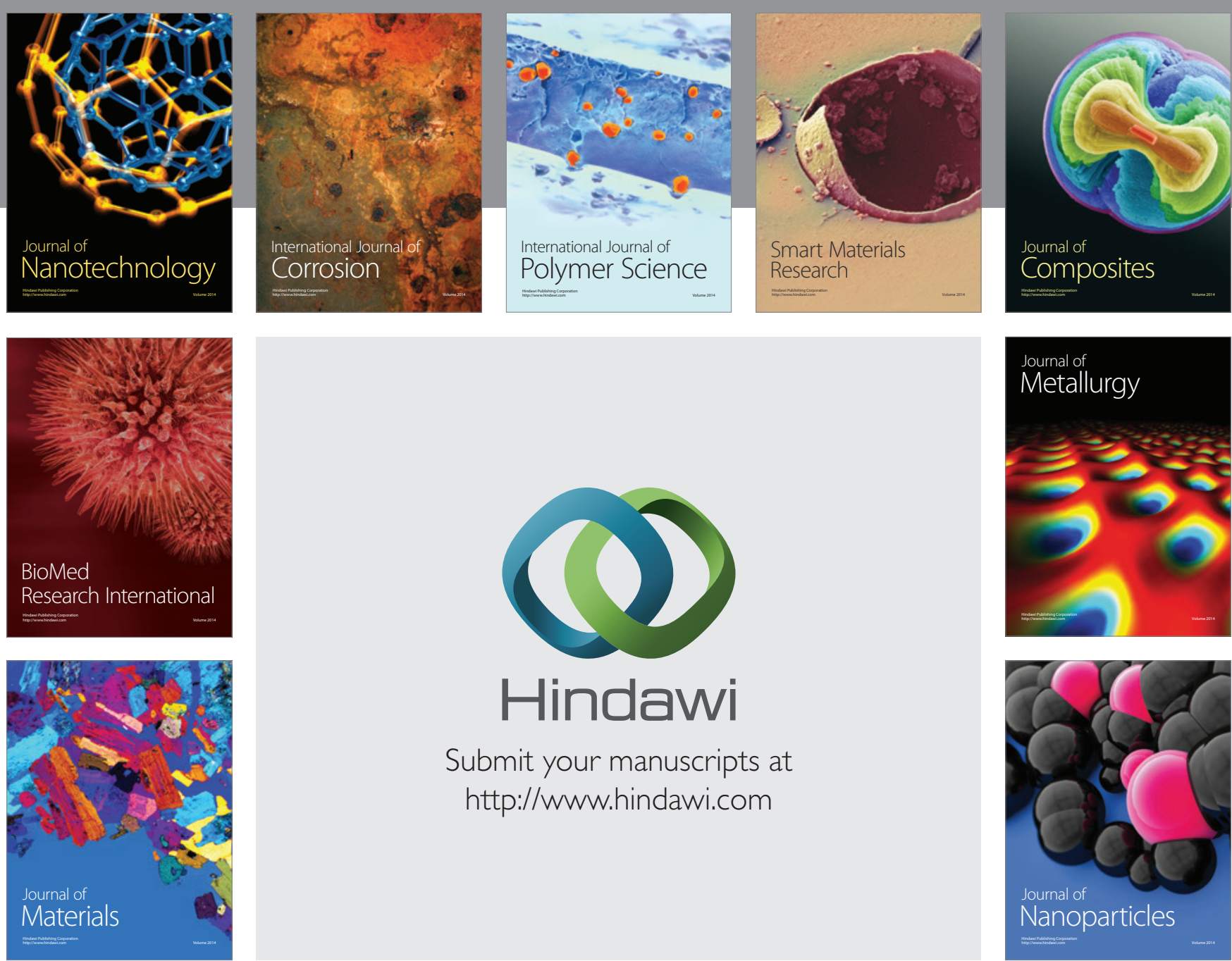

\section{Hindawi}

Submit your manuscripts at

http://www.hindawi.com

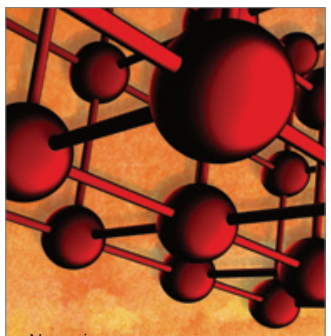

Materials Science and Engineering
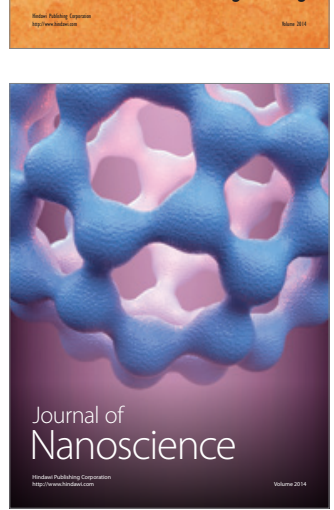
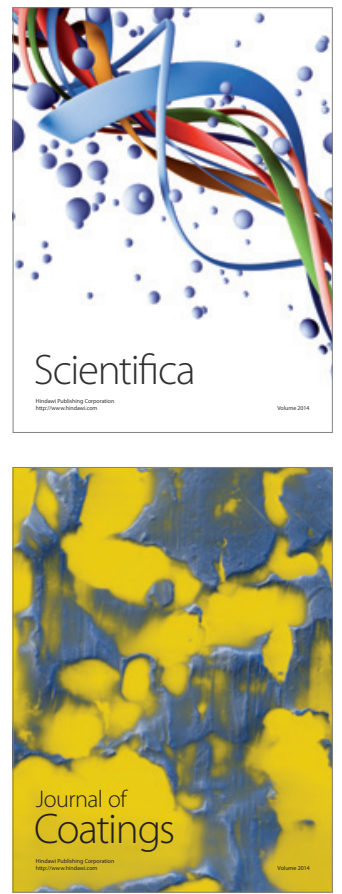
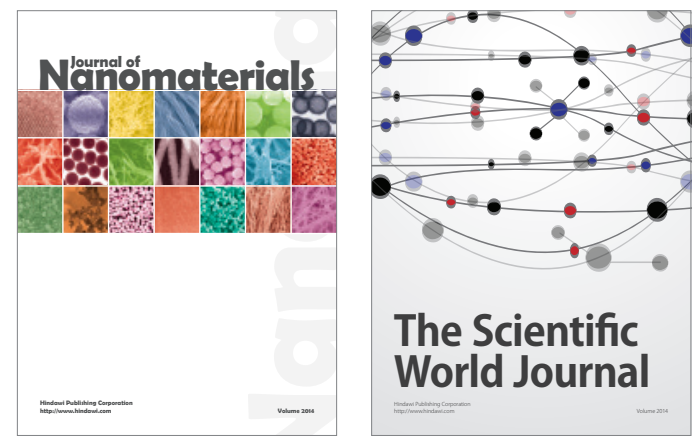

The Scientific World Journal
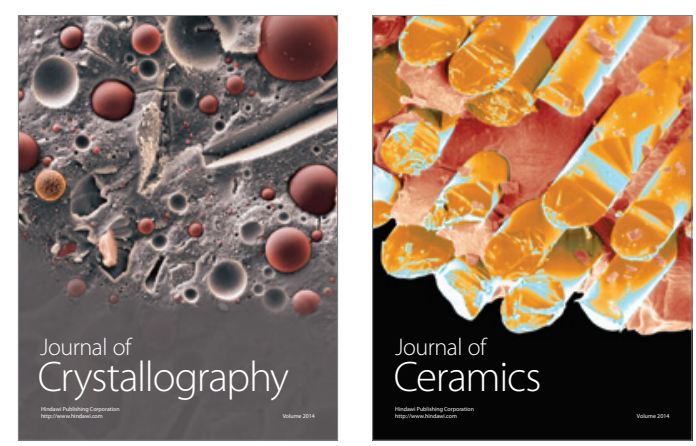
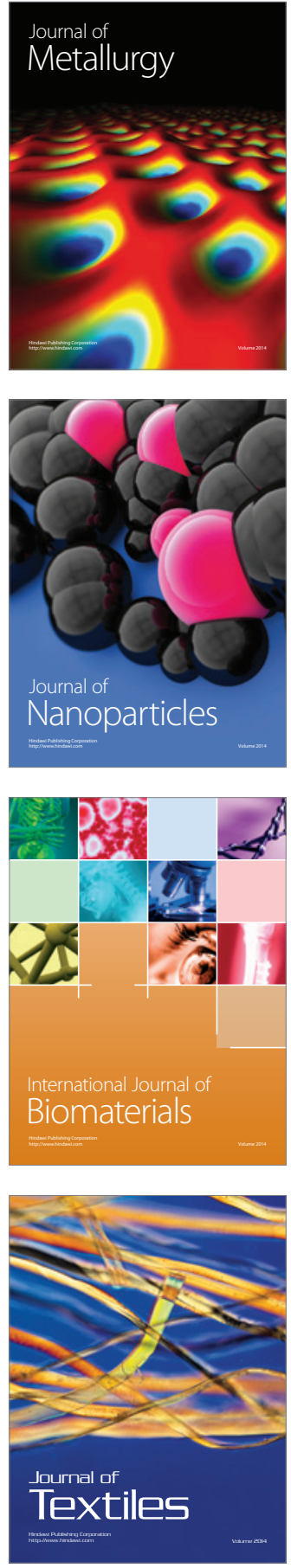